Studia Slavica Savariensia 2016. 1-2. 282-291

DOI: $10.17668 /$ SSS.2016.1-2.282

Marija Kozar-Mukič

(Sombotel, Madžarska)

\title{
LEPA VIDA S KAČO V MADŽARSKEM PREVODU AVGUSTA PAVLA IN PORABSKI PRAVLJICI
}

\begin{abstract}
The international motive ,a girl rescues the prince cursed into a snake" is well-known mostly in the prozaic tradition. It is preserved also in a tale from the Raba-region. Folk poems with this motive were written down in the Prekmurje-region. One of those poems was translated into Hungarian by Avgust Pavel, the first professional scientist from Prekmurje. He was born 130 years ago.
\end{abstract}

Keywords: Avgust Pavel, Beautiful Vida and the snake, folk poem, tale

Mednarodni motiv »dekle reši v kačo ukletega kraljeviča« je znan predvsem v proznem izročilu. Pesmi s tem motivom so se ohranile v Prlekiji in Prekmurju (TERSEGLAV 2005: 20). Avgust Pavel je prevedel inačico Od meje prekmurske, ki sta jo objavila Stanko Vraz in Karel Štrekelj v 19. stoletju (ŠTREKELJ 1895-1898: 131). Izvirniki in Pavlovi prevodi slovenskih ljudskih pesmi v madžarščino so izšli pri Pomurski založbi v Murski Soboti leta 1967, med njimi tudi pesem o Lepi Vidi s kačo. (NOVAK 1967: 104-107). Pravljico »Kralič pa Lejpa Vida« je na Verici v Porabju zapisal Karel Krajcar in jo lahko $\mathrm{v}$ izvirnem narečju ter prevodu Jožeta Ternarja v knjižno slovenščino beremo v knjigi založbe Kmečki glas iz leta 1996 (KRAJCAR 1996: 95-97).

Porabska pravljica v uvodu razloži, zakaj je kraljevič uklet v kačo. Mati je zgodaj zjutraj budila sina, naj vstane in gre k maši. Ko ga je drugič budila in ni vstal, ga je zaklela:

»Da bi se v kačo spremenio, ka ne bogaš pa neščeš $\mathbf{k}$ meša!« Ko tretjič stopi mati v sobo, se na tleh vlači kača in napove svojo rešitev: "Reiši me Jonaška Vida, ka se bo gnes rodila.« Ko je Vida postala štirinajst let stara, je zgodaj zjutraj šla proso plet, ki je bilo rosnato in steptano:

»Da je bila Vida štirinajst let stara, je šla zazranka rano plet proso na njivo. Velka rosa je bila. Ona si je pa gončala sama sebi: ... Da bi Bog dao, da bi to mo bilo, ka je töj odlo!« 
Ljudska pesem se zače s to epizodo:

1 Lepa Vida proso plela,

Jako rano pred zorjami.

Lepa Vida plela proso,

Stepeno je najšla roso:

5 »Da bi, Bog daj, mojo bilo,

Kaj nicoj je tod hodilo,

Kaj nicoj je tod hodilo,

Rano roso je strosilo!«

Pavel je prevedel prvih osem verzov v dveh kiticah, ravno tako z osmerci:

1 Vida kölest gaztalanít.

Alig pirkad meg a hajnal, máris a mezőre talpal.

Első reggel úgy találja,

5 hogy kölese megkuszálva, megvan törve harmatjába.

„Oh, bárcsak az enyém lenne, ami itt jár éjjelente."

Vida si želi pridobiti tistega, ki je roso steptal skoraj z istimi besedami v porabski pravljici, $\mathrm{v}$ slovenski ljudski pesmi in njenem madžarskem prevodu. Le da v Pavlovem prevodu Vida ne prosi pomoči Boga in poudari, da se to godi prvo jutro.

Druga kitica slovenske ljudske pesmi ima šest vrstic, madžarski prevod pa le pet osmercev.

Drugo jutro plela proso,

10 Stepeno je najšla roso:

»Da bi, Bog daj, mojo bilo,

Kaj nicoj je tod hodilo,

Kaj nicoj je tod hodilo,

Rano roso je strosilo!«

Másodnap is úgy találja,

10 hogy kölese megkuszálva,

meg van törve harmatjába.

„Oh, bárcsak az enyém lenne, ami itt járt éjjelente!” 
V slovenski kitici se ponavlja vrstica »Kaj nicoj je tod hodilo«. Tudi v porabski pravljici si Vida spet zaželi: »Da bi Bog dao, da bi to mo bilo, ka je töj odlo!«

Tretji dan je Vida $\mathrm{v}$ prosu našla kačo, $\mathrm{z}$ devetimi repi, na njih pa $\mathrm{z}$ devetimi ključi tako v slovenski pesmi, kot $\mathrm{v}$ Pavlovem prevodu. V porabski pravljici kača nima devetih repov z devetimi ključi.
15 Tretjo jutro proso plela,
Tam je najšla velko kačo.
Kača mela devet repov,
Na vsakšnem repi devet ključov:
Harmadik nap - uramfia! -
15 kígyót lát felé kusznia.
A kigyónak kilenc farka, s kilenc-kilenc kulcs csüng rajta.

$\mathrm{V}$ slovenski ljudski pesmi se prva in druga vrstica ne rimata. Pavel je $\mathrm{v}$ prevodu zaradi rim spremenil te dve vrstici in $\mathrm{z}$ medmetom izrazil Vidino začudenje:

Tretji dan - joj, prejoj meni! -

kačo vidi plezat' k sebi. (prevod avtorice)

Premi govor kače citira Pavel v prevodu v dveh kiticah po šest osmercev. V slovenščini je dvanajst vrstic premega govora vključenih $v$ šestnajstvrstično kitico.

»Ne straši se, lepa Vida!

20 Kaj si prosila, si dobila:

Saj sem jaz ne huda kača,

Saj sem jaz ne huda kača,

Al jaz sem ti mladi kraljič,

Ki kraljuje v belem gradi. -

25 Ti boš šla po gladkoj stezi,

Jaz pam šla po gostem germji;

Tam bova se mija zišla,

Na polji per belem gradi.

Tam vtergaj tri drobne šibe,

$30 \mathrm{Ki}$ bodo tri leta stare."

„Ne félj, Vida, ne ijedj meg!

Amit kértél, teljesedett. 
20 Nem vagyok én igazándi kígyó, hanem kis királyfi. Elhagyatott, puszta várban elvarázsolt kis királyfi." „Indulj meg a sima úton! 25 Én a csalitosban kúszom. Egy sík mezőn, váram alatt útjaink összeszaladnak. Mentedben mess három vesszőt, hároméves három vesszőt!"

V slovenski pesmi in porabski pravljici kača ogovori Vido s prilastkom »lepa«:

»Ne straši se, lepa Vida!« (slovenska pesem)

$»$ Ne boj se me, Leipa Vida« (porabska pravljica)

V madžarskem prevodu tega prilastka ni: „Ne félj, Vida, ne ijedj meg!” (dobesedno: Ne boj se, Vida, ne ustraši se!)

$\mathrm{V}$ vseh treh primerih razkrije kača, da je v resnici mladi kraljevič:

»Saj sem jaz ne huda kača,

Al sem ti mladi kraljič, « (slovenska pesem)

»Nem vagyok én igazándi

kígyó, hanem kis királyfi." (Pavlov prevod dobesedno: Nisem resnična kača, ampak mali kraljevič)

»Nej sem hüda kača, kralič sem mladi« (porabska pravljica)

V slovenski pesmi kraljevič $» k r a l j u j e ~ v$ belem gradi«, v porabski pravljici »Tam na tisto veliko brgjej stoji eden veltji grad«. V Pavlovem prevodu je kraljevič živel v zapuščenem, pustem gradu: »Elhagyatott, puszta várban«

$\mathrm{V}$ naslednjih dveh vrsticah slovenske pesmi in $\mathrm{v}$ Pavlovem madžarskem prevodu ter $\mathrm{v}$ porabski pravljici kača dá Vidi napotke, kako prideta do gradu. Vida bo šla po cesti, kača pa se bo plazila po grmovju:

»Ti boš šla po gladkoj stezi, Jaz pam šla po gostem germji;« (slovenska pesem)

„Indulj meg a sima úton! 
Én a csalitosban kúszom.” (Pavlov prevod)

»téj boš üšla po cesti, gja pa po grmovgja« (porabska pravljica)

V slovenski ljudski pesmi in njenem madžarskem prevodu mora Vida utrgati tri tri leta stare šibe, $v$ porabski pravljici pa tri enoletne leskove šibe.

»Tam vtergaj tri drobne šibe,

Ki bodo tri leta stare.« (slovenska pesem)

„Mentedben mess három vesszőt, hároméves három vesszőt!" (Pavlov prevod)

»Tan si vtrnaš tri leskove šibe, takšne, ka so eno leto zraščene...» (porabska pravljica)

Pavel je v prevodu s ponavljanjem in aliteracijo poudaril pravljično številko tri:

»három vesszőt,/hároméves három vesszőt" (tri šibe, / triletne tri šibe)

Zadnjo, šestnajstvrstično kitico je Pavel v prevodu razdvojil na sedem- in desetvrstično.

Da ga vujdre s pervoj šiboj,

On postane od glave človek;

Da ga vujdre $z$ drugoj šiboj,

On je do pojasa človek.

35 Te ga vujdre s tretjoj šiboj,

On postane do pet človek:

»Hala, hala, lepa Vida,

Kaj si štela, si dobila:

Vzemi, vzemi meni z repa,

$40 \mathrm{Z}$ mojega repa devet ključov,

No odkleni bele gradi,

No poberi srebro zlato!

Če sem bila grozna kača,

Pa sem ti zdaj mladi gospon,

$45 \mathrm{Ki}$ kraljuje v devet gradih

$\mathrm{Z}$ lepoj Vidoj nestrašlivoj.«
30 Hogy a kígyót megsuhintja

Egyik vesszejével Vida:

vállig ember lesz belőle.

Másik vesszősuhintástól

emberré lesz derekától.

35 Harmadiktól lábújjáig

gyönyörü ifjúvá válik.

»Lám ni, Vida, lám ni, lám ni!

Merni kell csak és kívánni!

Fogd a, fogd a kulcsaimat,

40 s nyisd ki kilenc váraimat!

És szedd össze a tömérdek

arany-, ezüst-, gyöngyértéket!

Kígyó voltam, megvedlettem,

újfent királyfivá lettem.

$45 \mathrm{~S}$ bátor veled kilenc várban

uralkodom boldogságban.« 
V slovenski ljudski pesmi in v Pavlovem madžarskem prevodu postane iz kače kraljevič postopno. Ko jo Vida udari s prvo šibo, postane »od glave človek«, pri Pavlu pa do ramen (,vállig ember”). Ko jo udari z drugo šibo, »on je do pojasa človek«, pri Pavlu prav tako »emberré lesz derekától«. Po tretjem udarcu »On postane do pet človek«, pri Pavlu do prstov na nogi postane čudovit mladenec „lábujjáig/gyönyörü ifjúvá válik.”

Porabska pravljica stopenj preobrazbe ne razčlenja. Vida kačo trikrat udari s tremi šibami, ki jih potem vrže proč od sebe. Po tretjem udarcu »se kralič vöpostavi«, kača se spremeni v kraljeviča. Pravljica se konča s splošno znano formulo: poročila sta se in sta še vedno v tistem gradu, če še živita. »Pa sta zdaj té na tisto brgjej v tisto gradej itak, če aštjak živita.«

Slovenska ljudska pesem in Pavlov madžarski prevod se konča s premim govorom kraljeviča, ki je bil zaklet v kačo. Pohvali lepo Vido, ker je bila vztrajna in pogumna. $\mathrm{S}$ tem je zaslužila devet ključev od devetih gradov $\mathrm{S}$ srebrom in zlatom, $\mathrm{v}$ katerih bosta skupaj kraljevala.

»Hala, hala, lepa Vida

Kaj si štela, si dobila:« (slovenska pesem)

Pavlov prevod:

„Lám ni, Vida, lám ni, lám ni!

Merni kell csak és kívánni!” (Glej jo, Vido, glej jo, glej! / Le upati si moraš in želeti!)

V slovenski ljudski pesmi nastane anahronizem, ko kraljič kot človek pravi Vidi:

»Vzemi, vzemi meni z repa,

$\mathrm{Z}$ mojega repa devet ključov«.

Pavel je to opazil in v njegovem prevodu pravi kraljevič Vidi: vzemi moje ključe, odpri mojih devetih gradov:

$»$ Fogd a, fogd a kulcsaimat, s nyisd ki kilenc váraimat!«

Pri vrsticah v slovenski ljudski pesmi:

»No odkleni bele gradi, No poberi srebro, zlato!« 
Pavlu uspe ohraniti osmerec tako, da k srebru in zlatu doda še bisere, ki jih je ogromno:

$$
\begin{aligned}
& \text { »És szedd össze a tömérdek } \\
& \text { arany-, ezüst-, gyöngyértéket.» }
\end{aligned}
$$

Pavel tudi $\mathrm{v}$ zadnji kitici ohranja osmerec, kljub temu jezikovno in vsebinsko tako prepesni slovensko ljudsko pesem, kot če bi nastala v madžarskem jeziku. Tako lahko prevaja nekdo, ki je tudi sam pesnik.

$\mathrm{Ob}$ 130. obletnici rojstva in 70. obletnici smrti Avgusta Pavla lahko ugotovimo, da tudi analiza le enega njegovega prevoda iz slovenščine $\mathrm{v}$ madžarščino dokazuje njegovo izredno pesniško nadarjenost, razgledanost, obvladovanje slovenskega in madžarskega jezika.

\section{Dodatek}

LEPA VIDA*

1 Lepa Vida proso plela, Jako rano pred zorjami. Lepa Vida plela proso, Stepeno je najšla roso:

5 »Da bi, Bog daj, mojo bilo, Kaj nicoj je tod hodilo, Kaj nicoj je tod hodilo, Rano roso je strosilo!«

Drugo jutro plela proso, 10 Stepeno je najšla roso: »Da bi, Bog daj, mojo bilo,

Kaj nicoj je tod hodilo, Kaj nicoj je tod hodilo, Rano roso je strosilo!«

15 Tretjo jutro proso plela, Tam je najšla velko kačo. Kača mela devet repov, $\mathrm{Na}$ vsakšnem repi devet ključov: »Ne straši se, lepa Vida!

* Vilko Novak (ur.): Slovenske ljudske pesmi $=$ Szlovén népdalok. Murska Sobota, 1967, 104-107.

\section{SZÉP VIDA}

1 Vida kölest gaztalanít. Alig pirkad meg a hajnal, máris a mezőre talpal. Első reggel úgy találja, 5 hogy kölese megkuszálva, megvan törve harmatjába. „Oh, bárcsak az enyém lenne, ami itt jár éjjelente."

Másodnap is úgy találja, 10 hogy kölese megkuszálva, meg van törve harmatjába.

„Oh, bárcsak az enyém lenne, ami itt járt éjjelente!"

Harmadik nap - uramfia! 15 kígyót lát felé kusznia.

A kigyónak kilenc farka, s kilenc-kilenc kulcs csüng rajta. „Ne félj, Vida, ne ijedj meg! Amit kértél, teljesedett. 
20 Kaj si prosila, si dobila:

Saj sem jaz ne huda kača,

Saj sem jaz ne huda kača,

Al jaz sem ti mladi kraljič,

$\mathrm{Ki}$ kraljuje $\mathbf{v}$ belem gradi. -

25 Ti boš šla po gladkoj stezi,

Jaz pam šla po gostem germji;

Tam bova se mija zišla,

Na polji per belem gradi.

Tam vtergaj tri drobne šibe,

$30 \mathrm{Ki}$ bodo tri leta stare."

Da ga vujdre s pervoj šiboj

On postane od glave človek;

Da ga vujdre z drugoj šiboj,

On je do pojasa človek.

35 Te ga vujdre s tretjoj šiboj,

On postane do pet človek:

»Hala, hala, lepa Vida,

Kaj si štela, si dobila:

Vzemi, vzemi meni z repa,

$40 \mathrm{Z}$ mojega repa devet ključov,

No odkleni bele gradi,

No poberi srebro zlato!

Če sem bila grozna kača,

Pa sem ti zdaj mladi gospon,

$45 \mathrm{Ki}$ kraljuje v devet gradih

Z lepoj Vidoj nestrašlivoj.«
20 Nem vagyok én igazándi

kígyó, hanem kis királyfi.

Elhagyatott, puszta várban

elvarázsolt kis királyfi."

„Indulj meg a sima úton!

25 Én a csalitosban kúszom.

Egy sík mezőn, váram alatt

útjaink összeszaladnak.

Mentedben mess három vesszőt, hároméves három vesszőt!"”

30 Hogy a kígyót megsuhintja

Egyik vesszejével Vida:

vállig ember lesz belöle.

Másik vesszősuhintástól

emberré lesz derekától.

35 Harmadiktól lábújjáig

gyönyörü ifjúvá válik.

»Lám ni, Vida, lám ni, lám ni!

Merni kell csak és kívánni!

Fogd a, fogd a kulcsaimat,

40 s nyisd ki kilenc váraimat!

És szedd össze a tömérdek

arany-, ezüst-, gyöngyértéket!

Kígyó voltam, megvedlettem

újfent királyfivá lettem.

$45 \mathrm{~S}$ bátor veled kilenc várban

uralkodom boldogságban.« 


\section{Kralič pa Lejpa Vida}

Gnauk je živeo eden kralič. Mati ga je zazranka rano gonila, da bi üšo k meša, ka so prvin krali pa bogati tü odkli k meša, bola kak srmaki.

Büdila ga je, da bi stano pa üšo k meša. Kralič pa nej stano. Prišla je od drügjin pa ga büdila, pa itak nej stano.

V tistem času je bila navada, ka je zakunila mati deita, tisto je postalo. Bila je čemerna pa me je praila:

»Da bi se v kačo spremenio, ka ne bogaš pa neščeš $\mathbf{k}$ meša!« Da je od tretjin odprla ižo, se je že kača po srtela sükala pa vlačila. Kralica se je prestaršila pa oblübila, da tistoma, steri ga reiši, dá telko peinez, kelko bo prosil.

Kralič, ta kača, pravi:

»Mati pa oča, vüva nejmate telko moudoša pa tak dugo nata živela, ka bi name reišila. Reiši me Jonaška Vida, ka se bo gnes rodila.«

Reisen, Vida se je rodila, rasla, on pa kača bijo tadala.

Da je bila Vida štirinajst let stara, je šla zazranka rano plet proso na njivo. Velka rosa je bila. Ona si je pa gončala sama sebi:

»Ka je tou bilo, da je rosa stepena, pa nejga nikšoga stopaja? Ka je töj odlo? Da bi Bog dao, da bi to mo bilo, ka je töj odlo!«

Na drügji zranjek pá tak bilo. Šla je na delo, prosa pá sé stepana bila. Sama sebi si pá gončala:

»Ka je töj odlo, da je rosa se stepana, pa nejga nikšoga stopaja?

Da bi Bog dal, ka bi to mo bilo, ka je töj odlo!«

Da na tretji zranjek pride, je bila $\mathrm{v}$ brazda ena velka kača. Vida se je tak prestrašila, da je prestrašeno skočila.

Kača pa pravi:

»Ne boj se me, Leipa Vida! Nej sem hüda kača, kralič sem mladi. Tej si sedi dola, gja se $\mathrm{k}$ tvoji nogam potegnem pa ti povejn, ka aj delaš, da me reišiš..."

Dobro, Vida je bougala pa si je sela. Kača se je k njej potegnila pa ji ja praila:

»Tam na tisti veliko brgjej stoji eden veltji grad, téj boš üšla po cesti, gja pa po grmovgja. Tan si vtrnaš tri leskove šibe, takšne, ka so eno leto zraščene pa tam name čakaj. Da gja priden, me z eno šibo ščukni pa go te lüči od sebe. Te me pa z drügo šibo ščukni pa go pa lüči od sebe. Ravno tak s tretjo šibo pa tisto tü lüči od sebe.«

Reisen, Leipa Vida je prišla v grad. Tam je bijo eden leskovi grn. Vtrnila je tri leskove šibe, ka so eno leto rasla. Te čas se je kača tü ta prvlekla. Vida je tak napraila, kak ji je kača velela. S prvo šibo go ščukna pa go liči od sebe, té pá z drügo ščukna pá go pa liči od sebe. Da go s tretjo ščukna, se kralič vöpostavi. Kača se spremeni v kraliča. 
Šlá sta v grad. Kral pa kralica sta trno rada bila. Velko gostüvanje so slüžili. Pa sta zdaj té na tisto brgjej v tisto gradej itak, če aštjak živita. ${ }^{*}$

\section{Literatura}

KRAJCAR 1996 = KRAJCAR K. Kralič pa Lejpa Vida: slovenske pravljice in povedke iz Porabja. Ljubljana 1996. 95-97.

NOVAK 1967 = NOVAK V. (ur.) Slovenske ljudske pesmi = Szlovén népdalok. Murska Sobota, 1967. 104-107.

ŠTREKELJ 1895-1898 = ŠTREKELJ K. Slovenske narodne pesmi I. Ljubljana, 18951898. 131.

TERSEGLAV $2005=$ TERSEGLAV M. Slovenske ljudske pesmi. Pripovedne 1. Ljubljana, 2005. 20.

* Karel Krajcar: Kralič pa Lejpa Vida: slovenske pravljice in povedke iz Porabja. Ljubljana 1996, 95-96. 